Bridging (Identification) Divides: Ethnic Minority Endorsement of New Diversity

Ideologies

\author{
Jessica Gale ${ }^{1}$, Kumar Yogeeswaran ${ }^{1}$, Maykel Verkuyten ${ }^{2}$ \\ ${ }^{1}$ University of Canterbury, New Zealand \\ ${ }^{2}$ ERCOMER, Utrecht University, Netherlands
}

Author notes:

Declaration of interest: none

The first author's contribution to this work is supported by the Swiss National Science Foundation (P2LAP1_187707)

Reference:

Gale, J., Yogeeswaran, K., \& Verkuyten, M. (2021). Bridging (identification) divides: Ethnic minority endorsement of new diversity ideologies. International Journal of Intercultural Relations, 81, 121-130. https://doi.org/10.1016/j.ijintrel.2021.01.00

Correspondence concerning this article should be addressed to Jessica Gale, School of Psychology, Speech and Hearing, University of Canterbury, Private Bag 4800, Christchurch 8140, New Zealand. E-mail: Jessica.gale@ canterbury.ac.nz 


\begin{abstract}
In culturally diverse societies, ethnic minorities are faced with the challenge of negotiating between their national and ethnic identification. Diversity ideologies address this challenge in different ways, by prioritizing national identification in the case of assimilation, and ethnic identification in the case of multiculturalism. However, existing research has highlighted the risks and drawbacks of both ideologies, presenting polyculturalism and interculturalism as new alternatives which construe identities as more complex, dynamic, and interconnected between groups. Given that little is known about these ideologies from the minority perspective, the present study investigated their endorsement among ethnic minorities, as well as associations with their ethnic and national identification in the USA. Results show that, in general, pro-diversity ideologies (multiculturalism, interculturalism, and polyculturalism) are all supported by ethnic minorities, in contrast to assimilation. Moreover, ethnic identification is associated with support for multiculturalism, national identification is associated with support for assimilation, and both are associated with polyculturalism. For interculturalism, associations with ethnic and national identification depend on its subcomponents, which seem to address and bring together the other three ideologies. Interculturalism may therefore be a promising way forward to minimize the risks of assimilation, multiculturalism, and polyculturalism, while also maximizing their benefits to minorities and societies at large.
\end{abstract}

Keywords: Interculturalism, Multiculturalism, Polyculturalism, Minority perspective, National identification, Ethnic identification 


\section{Bridging (Identification) Divides: Ethnic Minority Endorsement of New Diversity Ideologies}

In many contemporary societies, ethnic minorities ${ }^{1}$ face the challenge of negotiating between their ethnocultural identities and their identification with the larger society. Scholars, policymakers, and organizations are interested in understanding how to ideally manage this challenge as well as intergroup tensions associated with increasing diversity. One approach has been to favor the assimilation of minorities into dominant societies, encouraging them to identify with the country at large rather than with their ethnic group (Alba \& Nee, 2003; Gordon, 1964; Yinger 1981). Another approach has instead called for the multicultural recognition and celebration of differences and minorities' distinct ethnic group identities (see also Berry \& Kalin, 1995; Bloemraad, Korteweg, \& Yurdakul, 2008; Green \& Staerklé, 2013; Guimond et al., 2013; Koopmans, 2010; Novoa \& Moghaddam, 2014; Plaut, Garnett, Buffardi, \& Sanchez-Burks, 2011; Verkuyten, 2005; Wolsko, Park, \& Judd, 2006). Existing research has shown that, by and large, ethnic minorities tend to prefer the second approach as it is generally favorable to the presence of diverse groups and identities in society (Verkuyten, 2006; Wolsko et al., 2006; but see Tseung-Wong \& Verkuyten, 2018).

However, in many parts of the world including Europe and the United States, multiculturalism has been criticized for encouraging fragmentation along essentialized group lines. As a result, academic, public and policy discourse has proposed polyculturalism and interculturalism as alternative pro-diversity approaches that construe cultural identities as complex, dynamic, and interconnected between groups (Barrett, 2013; Bernardo et al., 2016; Meer \& Modood, 2012; Morris, Chiu, \& Liu, 2015; Verkuyten \& Yogeeswaran, 2020a). While recent research has examined how majority group members perceive these 'newer'

\footnotetext{
${ }^{1}$ We use the term "ethnic minority" to encompass both ethnic and racial minority groups in the United States, including Black/African American, Asian, Hispanic, Native American, and Multiracial. While the distinction between race and ethnicity is not without interest, it is not central to the present study which focuses on the minority perspective on diversity ideologies more generally.
} 
diversity ideologies (Rosenthal \& Levy, 2010, 2012; Verkuyten, Yogeeswaran, Mepham, \& Sprong, 2020), little or no research has examined their endorsement (or lack thereof) among ethnic and racial minorities. Therefore, we do not know whether minorities consider, for example, interculturalism as an alternative way for addressing questions of diversity. Moreover, if assimilation and multiculturalism are distinguished from each other primarily by the way in which they address minority identity (assimilation prioritizing national identification, and multiculturalism prioritizing ethnic identification; Guimond, de la Sablonnière, \& Nugier, 2014), then it is unclear how national and ethnic identification among minorities relates to their endorsement of polyculturalism and interculturalism in particular.

In the present research, we examine two central questions: (1) to what degree do ethnic and racial minorities endorse diversity ideologies of polyculturalism and interculturalism in comparison to multiculturalism and assimilation? And (2) to what extent are minority national and ethnic identification differentially associated with endorsement of each of these diversity ideologies? We examine these questions using survey data among ethnic and racial minorities in the USA.

\section{Diversity ideologies}

People have preferences in terms of how cultural diversity should be managed and show varying levels of support for different diversity ideologies. Within the social science literature, two widely discussed approaches to managing diversity include assimilation and multiculturalism (Bloemraad et al., 2008; Green \& Staerklé, 2013; Guimond et al., 2013; Koopmans, 2010; Verkuyten, 2005; Wolsko et al., 2006). Assimilationist strategies ask for minority groups and newcomers to give up their cultural identities and adopt the beliefs, norms, and practices of the dominant group in public life. Such an approach has been deemed problematic as it tends to produce negative intergroup outcomes including increased inequality and prejudice while undermining minority well-being and identity (Guimond et al., 
2014; Hahn, Banchefsky, Park, \& Judd, 2015; Verkuyten, 2010; Wolsko et al., 2006; see also recent meta-analyses by Leslie, Bono, Kim \& Beaver, 2020; Whitley \& Webster, 2019). Indeed, ethnic minorities generally show weak levels of support for assimilation (Verkuyten, 2006; Wolsko et al., 2006).

As an alternative, despite its many variations and interpretations (Gale \& Staerklé, 2019; Ward, Gale, Staerklé, \& Stuart, 2018), multiculturalism calls for the recognition and celebration of cultural differences, thereby allowing minority groups to maintain their unique identities. Multiculturalism has been shown to have positive benefits for intergroup relations by reducing majority group members' prejudice and increasing their positive behaviors toward minority groups (see Leslie et al., 2020; Whitley \& Webster, 2019, for metaanalyses). Moreover, the emphasis on ethnic identities inherent to multiculturalism is crucial, as research shows that minorities' larger distance from a societal "point of reference" (i.e., their lack of national prototypicality) means that their distinct group identification has more importance for their self-concept and well-being (relative to majorities; Deschamps, 1982; Gale \& Staerklé, 2019). By recognizing their ethnic group membership (positively), multiculturalism therefore legitimizes ethnic minorities' inclusion in society (Taylor, 1992). Indeed, it has been shown to predict increases in minority well-being and self-esteem, and ethnic minorities generally show strong levels of support for multiculturalism, especially relative to assimilation (Hehman et al., 2012; Plaut et al., 2018; Urbiola et al., 2017; Verkuyten, 2006, 2009a; Wolsko et al., 2006).

Nevertheless, despite the benefits of multiculturalism for minorities, research has highlighted its risks, especially in the USA and Europe where a backlash against multiculturalism has surfaced over recent decades (Barry, 2001; Joppke, 2014; Malik, 2015). Research has shown that, with its emphasis on cultural group differences in these contexts, multiculturalism can increase stereotypes and essentialist beliefs about minority groups, 
encouraging fragmentation along group lines (Bernardo et al., 2016; Wilton, Apfelbaum, \& Good, 2019; Wolsko, Park, Judd, \& Wittenbrink, 2000). It can also create conflict and negative intergroup outcomes when focused exclusively on minority groups, by leading majority group members to feel excluded (Plaut et al., 2011) and by increasing perceived threats to their ethnic and national identities (Morrison, Plaut, \& Ybarra, 2010; Tip et al., 2012; Yogeeswaran \& Dasgupta, 2014b).

Given the challenges faced by multiculturalism, recent research has begun to explore polyculturalism and interculturalism as alternative pro-diversity ideologies. Polyculturalism assumes that individuals' cultural identities and traditions are plural, interacting systems (Morris et al., 2015). The approach is similar to multiculturalism in that cultural and ethnic groups are recognized and valued, but the focus is on interconnectedness between these groups rather than on the differences between them (see Rosenthal \& Levy, 2010, 2016). This approach recognizes that people of different cultural backgrounds interact every day and have been interacting throughout history. Contemporary cultures and its members are shaped by these interactions, implying important intertwining between them. Boundaries between groups are therefore blurred. Nevertheless, polyculturalism differs from assimilation in its emphasis on celebrating peoples' cultural uniqueness and complexity, rather than encouraging them to give up their heritage and to adapt to a dominant group identity (Rosenthal \& Levy, 2012).

Research has found that polyculturalism can overcome the risk of 'parallel societies' (Sen, 2006), ethnic segregation (Sears, Citrin, Cheleden, \& van Laar, 1999), and perceived group essentialism (Bernardo et al., 2016) that is associated with multiculturalism's strong emphasis on differences between cultural groups. Moreover, studies show that polyculturalism is associated with pro-diversity attitudes like multiculturalism, and contrasts with assimilationist attitudes (see Rosenthal \& Levy, 2012). In the present study, we explore 
whether ethnic minorities more strongly endorse polyculturalism than multiculturalism, given its benefits highlighted above, or whether the somewhat assimilationist connotation focusing on the mixing of identities rather than group distinctiveness might make it a less preferred pro-diversity ideology among ethnic minorities.

Similar to polyculturalism, interculturalism is another diversity ideology that has been put forward as an alternative to multiculturalism through, for example, policies, education and also research (Verkuyten et al., 2020). Despite some variations and different usages of this term depending on the national context, the Council of Europe and UNESCO, for example, have adopted an "intercultural policy" whereby cultures are encouraged to interact (positively) in public spaces through "intercultural dialogue" (Council of Europe, 2008; UNESCO, 2009). Political philosophers and scientists consider this European version of interculturalism to emphasize the three components of unity, identity flexibility, and dialogue (for a review, see Meer, Modood, \& Zapata-Barrero, 2016). Specifically, interculturalism (a) promotes national unity and commonalities against the backdrop of cultural differences, (b) promotes new flexible, mixed, and changeable forms of identity, including hybrid identities and mixed race individuals, through recognition of cultural fusions and blending of cultures, and (c) promotes intergroup dialogue as key to promoting positive relations in diverse countries, all at the same time.

Empirical research has established that these three features of interculturalism collectively emerge as components of an overarching interculturalism construct in lay people's understanding (Verkuyten et al., 2020). Importantly, studies from the USA, the Netherlands, and New Zealand also establish that interculturalism improves majority group members' attitudes and behaviors toward ethnic minority groups, and increases their desire for intergroup contact (Verkuyten \& Yogeeswaran, 2020b; Yogeeswaran, Verkuyten, \& 
Ealam, 2020). However, no research has examined whether ethnic minorities endorse interculturalism as a strategy for managing diversity.

Recent research has also shown that among majorities, interculturalism is positively associated with multiculturalism, and negatively associated with assimilation (Verkuyten et al., 2020). While no research has empirically examined its association with (or distinctiveness from) polyculturalism, interculturalism's identity flexibility component is what theoretically brings them closest together. Both of these ideologies indeed emphasize interconnectedness and mutual influence between cultural groups. The main distinguishing feature is that polyculturalism implies a rather descriptive construal of how societies and individuals function and have historically functioned, whereas identity flexibility (and interculturalism more generally) involves prescriptive beliefs regarding how societies and individuals ought to function (see Verkuyten et al., 2020; Yogeeswaran et al., 2020). We therefore explored whether ethnic minority endorsement of interculturalism differs depending on the feature of interculturalism under scrutiny (i.e., identity flexibility, dialogue, unity), and how these three features relate to endorsement of other diversity ideologies.

\section{Identification and Diversity Ideologies}

The second goal of the present research is to examine how minority members' ethnic and national identification are associated with their endorsement of polyculturalism and interculturalism, in addition to multiculturalism and assimilation. When examining how people can consider their group membership to be at different levels of self-categorization, social psychologists have made a distinction between subgroup and superordinate identification (e.g., Dovidio, Gaertner, \& Saguy, 2009; Dovidio, Gaertner, Ufkes, Saguy, \& Pearson, 2016; Turner, Hogg, Oakes, Reicher, \& Wetherell, 1987). Among ethnic minorities, this can refer to their ethnic and national identification, in particular. As Guimond et al. 
(2014) point out, diversity ideologies are defined and distinguished from each other by the different ways in which they address minority ethnic and national identification.

Given that minority identity is a key feature of diversity ideologies and that social identities provide a lens through which people make sense of the world and through which attitudes are shaped (Reicher, Spears, \& Haslam, 2010), the way in which a minority group member construes their sense of identity should be associated with their support for particular diversity ideologies. By definition, for example, assimilation prioritizes national identification by recategorizing subgroup identities into a superordinate, national category (Gaertner, Dovidio, Anastasio, Bachman, \& Rust, 1993; Guimond et al., 2014). Furthermore, national identification among minorities can imply the legitimization of the status quo and existing inequalities (see for example Bilali, 2014), which assimilation is known to do (Levin et al., 2012). Research shows that the more strongly people identify with a given country, the more strongly they support an approach to managing cultural diversity which favors and preserves nationally defining beliefs, norms and values (Verkuyten \& Martinovic, 2012; Yogeeswaran \& Dasgupta, 2014a). In the present study, given the United States' melting pot analogy, higher national identification among ethnic minorities is expected to be associated with stronger support for assimilation.

National identification has sometimes been shown to be associated with support for multiculturalism among minorities (see Grant \& Robertson, 2014; Ng Tseung Wong \& Verkuyten, 2016), but only when the country itself is defined by multicultural norms and when minorities are therefore encouraged to identify with their ethnic group as well (see also Nandi \& Platt, 2015). Multiculturalism, by definition, encourages minorities to identify with their ethnic group. Indeed, the more minorities identify with their ethnic group, the more they may reject assimilation (Verkuyten, 2005) and support, instead, an approach which (sometimes) functions to contest the status quo and existing inequalities like multiculturalism 
(see also Simon, 2011). It is therefore likely that ethnic identification is predominantly associated with support for multiculturalism among minorities, particularly in a melting pot country like the USA.

The link between minority ethnic and national identification with polyculturalism is harder to predict because polyculturalism, by definition, views identities in a nuanced fashion (Morris et al., 2015; Rosenthal \& Levy, 2010, 2012, 2016). Some studies on polyculturalism have included measures of identification (Bernardo, Rosenthal, \& Levy, 2013; Rosenthal, Levy, \& Moss, 2012), showing that both national (Bernardo et al., 2013, Study 1) and ethnic (Rosenthal et al., 2012, Study 2) identification are positively associated with support for this diversity ideology. However, these studies were conducted primarily among majority group members and therefore provide limited insight into minority identifications and polyculturalism.

In a similar way, it is unclear how minorities' identification with their ethnic and national group relates to their endorsement of interculturalism. As interculturalism involves the three interrelated components of unity, identity flexibility, and dialogue, it may be that both group identifications have a nuanced relationship with endorsement of each of these components. For example, the unity component of interculturalism, with its focus on commonalities between people within a country (despite their differences), could have a stronger relationship with national identification, similar to assimilation. However, identity flexibility and dialogue could show strong relationships with both ethnic and national identification among minorities, as these components of interculturalism imply generally bringing people and groups together alongside their differences, similar to polyculturalism.

Accordingly, after examining the degree to which ethnic minorities support interculturalism and polyculturalism as new diversity ideologies, we explore how their ethnic and national identification relate to this support, and how these associations compare to the 
relations between ethnic and national identification with endorsement of assimilation and multiculturalism.

\section{Method}

\section{Participants}

Participants were recruited online by Qualtrics' panel services which maintain a large national database of American adults. The total sample for the study included 418 adult ethnic minority U.S. citizens from around the country. Participants came from various parts of the USA, with the largest proportions living in California (12\%), Florida (7\%), Illinois, Texas, and New York (6\% each), and the rest dispersed across an additional 38 states. After excluding those who completed the questionnaire abnormally fast (two times faster than the median speed of the sample, see Leiner, 2013), the final sample included 349 participants. $^{2}$ The majority self-identified as "Black or African American" $(n=188)^{3}$, and substantial portions self-identified as “Asian American" $(n=63)$, "Hispanic” (but not White; $n=47)$, "Multiracial American" $(n=17)$, or "Native American or Alaska Native" ( $n=16$; the remainder were mostly mixed race). The sample was composed primarily of women (73\%), ages ranged from 18 to 73 years $(M=36.87, S D=14.17)$, almost all participants had at least completed high school (98\%; $28 \%$ having high school as their highest level of education and $28 \%$ having completed at least a Bachelor degree), and the median income was in the range of $\$ 25,000$ to $\$ 50,000$ per year (29\% of participants within this range, $25 \%$ making less than $\$ 15,000$ per year, and $12 \%$ making more than $\$ 100,000$ per year).

\section{Measures}

All measures used a 7-point Likert scale ranging from 1 (strongly disagree) to 7 (strongly agree) (see supplementary material for exact item wording).

\footnotetext{
${ }^{2}$ Findings are similar when analyses are conducted on the full sample.

${ }^{3}$ We also conducted all analyses on this African American sub-sample. Unless indicated otherwise, interpretation of results was identical.
} 
Assimilation ideology. Three items taken from Guimond et al. (2014) were used to assess support for assimilation $(\alpha=.83)$, for example, "People who come to the US should change their behavior to be more like Americans". ${ }^{4}$

Multicultural ideology. Support for multiculturalism was assessed using five items taken from previous work (Rosenthal \& Levy, 2012; $\alpha=.84$ ), for example, "There are differences between racial and ethnic groups, which are important to recognize".

Polycultural ideology. Support for polyculturalism was measured using five items taken from previous work (Rosenthal \& Levy, 2012; $\alpha=. .85$ ), for example, "Different racial, ethnic, and cultural groups influence each other".

Intercultural ideology. Support for interculturalism was measured using 12 items, divided into the three sub-dimensions and taken from Verkuyten et al. (2020). The overarching factor of interculturalism was reliable $(\alpha=.89)$, as were the four items forming each of the subscales (sense of unity IU, $\alpha=.82$, for example, "Despite cultural differences, all groups together form American society"; identity flexibility IF, $\alpha=.74$, for example, "The cultural identity of people is not fixed, but very changeable"; and dialogue ID, $\alpha=.89$, for example, "Only by really listening to each other, differences can be reconciled").

National identification was assessed using four items adapted from previous research (Luhtanen \& Crocker, 1992; Phinney \& Ong, 2007; Postmes, Haslam, \& Jans, 2013; $\alpha=.93$ ), for example, "I identify with America".

Ethnic identification was measured using the same four items referring to identification with "my ethnic/racial group" instead of the national group $(\alpha=.92)$.

\footnotetext{
${ }^{4}$ Four items taken from Hahn et al. (2015) measuring assimilation were also available in the dataset. When using these items in lieu of the reported three items, interpretation of results was the same.
} 


\section{Results}

\section{Testing Factorial Structure}

Prior to hypothesis testing, we checked that our measured constructs were empirically distinct from one another. To do so, a confirmatory factor analysis was conducted with Mplus Version 8.2 (Muthén \& Muthén, 1998-2018) on the total 33 items presented above. Cut-off criteria of fit indices were determined according to $\mathrm{Hu}$ and Bentler (1999) and Lai and Green (2016), and model comparisons were made using chi-square difference scores as well as Akaike Information Criteria (AIC).

A model was first examined in which all 33 items loaded on a single factor and model fit was poor $\chi^{2}(495)=4420.43, \mathrm{AIC}=40469.21, \mathrm{CFI}=.45, \mathrm{RMSEA}=.15, \mathrm{SRMR}=.13 . \mathrm{A}$ second model including the six factors representing the four diversity ideologies as well as the two identifications was then tested and although model fit was significantly better than the first model, $\Delta \chi^{2}(15)=2991.7, p<.001$, the fit was still unsatisfactory, and borderline acceptable, $\chi^{2}(480)=1428.77, \mathrm{AIC}=37507.54, \mathrm{CFI}=.87, \mathrm{RMSEA}=.08, \mathrm{SRMR}=.07$; Indeed, a third model including eight factors representing the three components of interculturalism as well as the three other diversity ideologies and the two identification measures was then tested and the model fit was satisfactory, $\chi^{2}(467)=966.80, \mathrm{AIC}=$ $37071.57, \mathrm{CFI}=.93, \mathrm{RMSEA}=.06, \mathrm{SRMR}=.06$, and was significantly better than the second model, $\Delta \chi^{2}(13)=461.97, p<.001$. This shows that all diversity ideologies (including interculturalism divided into its three components) and ethnic and national identification loaded on separate factors.

A fourth model which was the same as the third model but which incorporated a supplementary second order factor predicting the three components of interculturalism was finally calculated and the model fit was also satisfactory, $\chi^{2}(477)=1043.90, \mathrm{AIC}=37128.67$, $\mathrm{CFI}=.92, \mathrm{RMSEA}=.06, \mathrm{SRMR}=.07$, although less so than the previous model, $\Delta \chi^{2}(10)=$ 
$77.11, p<.001$. Because the overall alpha for the single, overarching interculturalism scale was good and because the fit of the model including a second order factor was satisfactory, we not only focus our analysis on the three dimensions of interculturalism separately ${ }^{5}$ but also show results for interculturalism as a single construct.

\section{Comparing Endorsement of Diversity Ideologies}

Table 1 shows means, standard deviations, and correlations for all latent variables (including interculturalism as an overarching factor and with its three components). Of particular importance for the first research question, participants generally showed rather favorable attitudes towards pro-diversity ideologies (multiculturalism, polyculturalism, and interculturalism), but less favorable attitudes towards assimilation where the sample mean was below the midpoint of the scale. After identifying relative latent variable means via the effect coding method (see Little, Slegers, \& Card, 2006), Wald Chi-square tests showed that support for multiculturalism was marginally stronger than support for polyculturalism, Wald $\chi^{2}(1)=5.63, p=.018$ (Bonferroni corrected critical $p$-value $\left.=.017\right),{ }^{6}$ and that there was no difference between support for multiculturalism and interculturalism, Wald $\chi^{2}(1)=0.77, p=$ .380 , nor between polyculturalism and interculturalism, Wald $\chi^{2}(1)=1.54, p=.214$. Among the interculturalism's sub-components, dialogue was the most preferred, followed by unity which was supported less than dialogue, Wald $\chi^{2}(1)=54.64, p<.001$, and finally identity flexibility which was supported less than unity, Wald $\chi^{2}(1)=15.60, p<.001$.

\footnotetext{
${ }^{5}$ The factorial structure of only interculturalism was also tested using confirmatory factor analysis. When all 12 items loaded on a single factor, model fit was poor, $\chi^{2}(54)=546.80, \mathrm{AIC}=14099.16, \mathrm{CFI}=.76, \mathrm{RMSEA}=.16$, $\mathrm{SRMR}=.09$. However, a three-factor model distinguishing between interculturalism's components showed good fit, $\chi^{2}(51)=155.45, \mathrm{AIC}=13713.80, \mathrm{CFI}=.95, \mathrm{RMSEA}=.08, \mathrm{SRMR}=.05$; significantly better than the single-factor model, $\Delta \chi^{2}(3)=391.36, p<.001$. Finally, a third model in which the three factors were forced to be orthogonal to one another was also examined and the model fit was once again poor, $\chi^{2}(54)=458.66, A I C=$ $14011.01, \mathrm{CFI}=.80, \mathrm{RMSEA}=.15, \mathrm{SRMR}=.27$. This confirms that the three dimensions of interculturalism are conceptually distinct but strongly associated with one another.

${ }^{6}$ When conducting analyses on the African American sub-sample, support for multiculturalism $(M=5.22)$ was significantly stronger than support for polyculturalism $(M=4.99 ; p<.001)$.
} 
Correlations show that the pro-diversity ideologies were all strongly positively correlated to each other. Moreover, assimilation stood separately from the rest; its only (weak) positive correlation was with the identity flexibility component of interculturalism. It is also worth noting that national and ethnic identification were positively correlated $(r=$ .33), suggesting that the more participants identified with their ethnic group, the more they also tended to identify with the USA.

\section{Table 1}

Means (standard deviations) and correlations between identification and diversity ideology variables

\begin{tabular}{|c|c|c|c|c|c|c|c|c|c|}
\hline Variable & $M(S D)$ & 2. & 3. & 4. & 5. & 6. & 7. & 8. & 9. \\
\hline 1. AS & $3.57(1.50)$ & .02 & .03 & .03 & .08 & $.17 * *$ & -.11 & $.26 * * *$ & $-.12 *$ \\
\hline 2. $\mathrm{MC}$ & $5.23(0.99)$ & & $.81 * * *$ & $.70 * * *$ & $.45 * * *$ & $.50 * * *$ & $.67 * * *$ & $.22 * * *$ & $.41 * * *$ \\
\hline 3. $\mathrm{PC}$ & $5.12(1.03)$ & & & $.81 * * *$ & $.58 * * *$ & $.55^{* * *}$ & $.77 * * *$ & $.24 * * *$ & $.31 * * *$ \\
\hline 4. IC & $5.18(1.05)$ & & & & & & & $.27 * * *$ & $.38 * * *$ \\
\hline 5. IU & $5.10(1.27)$ & & & & & $.66 * * *$ & $.63 * * *$ & $.39 * * *$ & $.22 * * *$ \\
\hline 6. IF & $4.84(0.99)$ & & & & & & $.69 * * *$ & $.23 * * *$ & $.27 * * *$ \\
\hline 7. ID & $5.59(1.16)$ & & & & & & & $.19 * *$ & $.37 * * *$ \\
\hline 8. NatID & $5.08(1.66)$ & & & & & & & & $.33 * * *$ \\
\hline 9. EthID & $5.31(1.57)$ & & & & & & & & \\
\hline
\end{tabular}

Note. AS represents assimilation, MC represents multiculturalism, PC represents polyculturalism, IU represents Sense of Unity dimension of Interculturalism, IF represents Identity Flexibility dimension of Interculturalism, ID represents Dialogue dimension of Interculturalism. 


\section{Examining the Relationship between Minority Identification and Diversity Ideologies}

To examine whether and how national and ethnic identification are associated with the diversity ideologies, we used structural equation modelling (SEM). National and ethnic identification were included as distinct predictors of each of the diversity ideologies. ${ }^{7}$ All were latent variables and when age, gender, education, income and ethnicity were included as control variables, interpretation of results was identical (see Table A1 in supplementary material).

In a first model, we included the four main diversity ideologies as outcomes, with interculturalism as a single construct (see the second CFA model presented above). Regression coefficients showed that both national and ethnic identification were positively associated with interculturalism (respectively $b=.12,95 \% C I[.04, .20], S E=.04, p=.004 ; b$ $=.22,95 \% C I[.13, .31], S E=.05, p<.001)$. Results for the other three diversity ideologies were the same as in the final model, reported next.

In a second model, we included the three different components of interculturalism together with the other diversity ideologies as outcomes (see the third CFA model presented above). Standardized regression coefficients, standard errors, and confidence intervals are summarized in Table 2.

National identification was positively associated with assimilation and with polyculturalism, as well as with the sense of unity (IU) and identity flexibility (IF) dimensions of interculturalism. Ethnic identification was negatively associated with assimilation and was positively associated with multiculturalism and with polyculturalism, as well as with the identity flexibility (IF) and dialogue (ID) dimensions of interculturalism.

\footnotetext{
${ }^{7}$ Confirmatory factor analysis showed that the model including two dimensions of identity $\left(\chi^{2}(19)=94.16, A I C\right.$ $=9129.33, \mathrm{CFI}=.97, \mathrm{RMSEA}=.11, \mathrm{SRMR}=.03)$ fit the data significantly better than the model in which all eight identity items loaded on one single dimension $\left(\chi^{2}(20)=1091.70, \mathrm{AIC}=10124.88, \mathrm{CFI}=.54, \mathrm{RMSEA}=.39, \mathrm{SRMR}\right.$ $=.24), \Delta \chi^{2}(1)=997.54, p<.001$.
} 


\section{Table 2}

Standardized regression coefficients (standard errors) and confidence intervals for model including national and ethnic identification predicting six diversity ideologies

\begin{tabular}{|c|c|c|c|c|}
\hline \multirow[b]{2}{*}{ Diversity ideology } & \multicolumn{2}{|c|}{ National identification } & \multicolumn{2}{|c|}{ Ethnic identification } \\
\hline & $b(S E)$ & $95 \% C I$ & $b(S E)$ & $95 \% C I$ \\
\hline AS & $.33 * * *(.06)$ & {$[.22, .45]$} & $-.23 * * *(.06)$ & {$[-.35,-.12]$} \\
\hline $\mathrm{MC}$ & $(.06)$ & {$[-.02, .21]$} & $.38 * * *(.06)$ & {$[.27, .49]$} \\
\hline $\mathrm{PC}$ & $(.06)$ & {$[.03, .27]$} & $.26 * * *(.06)$ & {$[.15, .38]$} \\
\hline IU & $.36 * * *(.06)$ & {$[.25, .47]$} & $(.06)$ & {$[-.01, . .22]$} \\
\hline IF & $(.07)$ & {$[.03, .28]$} & $.22 * * \quad(.06)$ & {$[.10, .35]$} \\
\hline ID & $(.06)$ & {$[-.05, .19]$} & $.35 * * *(.06)$ & {$[.24, .46]$} \\
\hline
\end{tabular}

Note. AS represents assimilation, MC represents multiculturalism, PC represents polyculturalism, IU represents Sense of Unity dimension of Interculturalism, IF represents Identity Flexibility dimension of Interculturalism, ID represents Dialogue dimension of Interculturalism. $b$ represents unstandardized regression coefficients, $S E$ represents standard error, $95 \% \mathrm{CI}$ represents $95 \%$ confidence interval.

$* * * p<.001, * * p<.01, * p<.05$.

Comparing the three dimensions of interculturalism and the three other diversity ideologies indicates that dialogue (ID) and multiculturalism showed a similar pattern of relationships with group identifications: National identification was not related to either ideology, in a similar way, Wald $\chi^{2}(1)=0.00, p=.950$, and ethnic identification was positively related to both, also in a similar way, and Wald $\chi^{2}(1)=0.83, p=.361$. Furthermore, identity flexibility (IF) and polyculturalism showed a similar pattern of relationships whereby both national and ethnic identification had positive associations that were equally strong, Wald $\chi^{2}(1)=0.06, p=.804$, and Wald $\chi^{2}(1)=1.14, p=.286$, respectively. Finally, sense of unity (IU) and assimilation showed a similar positive 
association with national identification, Wald $\chi^{2}(1)=0.00, p=.987$. However, whereas ethnic identification was negatively associated with assimilation, ethnic identification tended to be positively related ( $p=.084$ ) with the unity dimension of interculturalism, and these associations were significant different from each other, Wald $\chi^{2}(1)=15.42, p<.001$. In other words, unlike assimilation, the unity dimension of interculturalism did not seem to pit national and ethnic identification against each other among ethnic minorities.

\section{Discussion}

The present study had two overarching goals: (1) to examine levels of endorsement of intercultural and polycultural diversity ideologies compared to the more common approaches of assimilation and multiculturalism with an ethnic minority sample, and (2) to look at how national and ethnic identification among ethnic minorities are associated with endorsement of assimilation, multiculturalism, polyculturalism, and interculturalism ideologies.

With regards to the first research question and consistent with existing research (Verkuyten, 2005; Wolsko et al., 2006), we found that compared to assimilation, ethnic minorities prefer multiculturalism as an approach to managing diversity. Yet, while support for multiculturalism was particularly strong, support for interculturalism was not significantly different, and support for polyculturalism was not far off either (only marginally less supported than multiculturalism).

Nevertheless, when interculturalism was divided into its subdimensions, we did find important nuances in ethnic minority endorsement of this ideology. Specifically, dialogue was most strongly supported, followed by unity, and finally, identity flexibility. It therefore seems that ethnic minorities are most concerned about establishing effective communication with other cultural groups in society (including majorities) via pro-diversity ideologies, rather than meshing their ethnic identity together with other (e.g., nationally dominant) ones. While establishing social unity and intermixing between identities is also important to them, this is 
secondary and may complement, rather than undermine, this more foundational interest in intergroup communication. The fact that unity was more strongly supported than identity flexibility, however, may by driven by the idea that unity, within the context of interculturalism, faintly acknowledges the backdrop of differences (and therefore, to some extent, ethnic minority distinctiveness), while identity flexibility explicitly encourages the merging of identities (see below). With that said, our ethnic minority sample largely supported all pro-diversity ideologies (including interculturalism's subcomponents; all means were above the midpoint of the scale), and opposition was only shown towards assimilation, the ideology which is less favorable to diversity. This is important to consider when trying to determine which approach is likely to best satisfy the needs and preferences of both minorities and majorities alike.

Results concerning ethnic and national identification (i.e., the second research question) converged with the above interpretations. Indeed, if protecting their distinctive ethnic identity is of importance to minorities (see also Deschamps, 1982; Gale \& Staerklé, 2019), ethnic identification would be significantly associated with their endorsement of multiculturalism, which is the case here. Similarly, national identification was positively associated with support for assimilation and ethnic identification was negatively associated with support for this diversity ideology. This is because assimilation is focused primarily on superordinate national identification (Guimond et al., 2014), and research shows that conceptions of national identity in the USA seem to coincide with White ethnic identity, thereby excluding minority identities (Devos \& Mohamed, 2014; Yogeeswaran \& Dasgupta, 2014a).

But many ethnic minorities not only feel strongly identified with their ethnic group; they can also have high levels of national identification, too. Examining the relationships between national and ethnic identification with support for polyculturalism and 
interculturalism (as an overarching construct) showed how both ethnic and national identification are simultaneously associated with support for these diversity ideologies. This is interesting as both polyculturalism and interculturalism attempt to overcome the respective drawbacks and risks of multiculturalism and assimilation, thereby creating a bridge between the two (Meer et al., 2016; Morris et al., 2015). The result is also consistent with the idea that both of these ideologies prioritize all identities to the same degree (because identities are viewed as intermixing; Rosenthal \& Levy, 2010, 2012, 2016; Verkuyten et al., 2020).

Nevertheless, when examining relationships between identification and interculturalism divided into its sub-components, nuances became apparent. In particular, results for identity flexibility as a component of interculturalism and polyculturalism were the same. Therefore, the conceptual definitions of polyculturalism and identity flexibility as similarly addressing minority (intermixing) identity dynamics are supported by our data. It is important to remember that polyculturalism and identity flexibility were also both, respectively, the least favored pro-diversity ideologies among our ethnic minority sample (despite that support for polyculturalism was just as strong as support for the composite version of interculturalism), perhaps because they ignore a basic concern for their distinct ethnic group membership (Brewer, 1991).

In a similar fashion, the dialogue component of interculturalism overlaps with multiculturalism in that only ethnic identification (not national identification) was positively associated with both. The original political definition of multiculturalism does highlight effective communication between distinct cultural groups as a basic objective (Kymlicka, 2012). Thereby, while groups may be considered to be fixed and distinct, risking essentialism and segregation under multicultural thought (Wilton et al., 2019), this may not be the way ethnic minorities interpret the ideology. Ethnic minorities (particularly those who feel a 
pronounced sense of attachment to their ethnic group) also seem to place high value on dialogue and intergroup communication.

Finally, results for unity as a component of interculturalism and assimilation were rather similar. Specifically, national identification was the only form of identification that was positively associated with both assimilation and unity. This is unsurprising given their respective emphasis on national cohesion. Nevertheless, unlike assimilation, ethnic identification was not negatively associated with unity - the relationship was even marginally positive. Therefore, this component of interculturalism (at least in the USA) may serve as a more inclusive approach to establishing social cohesion by avoiding disapproval of minorities who feel strongly connected to their ethnic group.

It therefore appears that the three components of interculturalism manage to grasp identity dynamics inherent to the other three diversity ideologies, in line with its philosophical underpinnings. In this way, interculturalism, as a conceptual whole, might create a bridge between assimilation, multiculturalism, and polyculturalism. If each of these diversity ideologies has their respective weaknesses, then interculturalism may serve to overcome them, so long as ethnic minorities' need for both inclusion and distinctiveness (Brewer, 1991), and communication, remains intact.

\section{Limitations and Future Directions}

A strength of the present study was its focus on a sample of ethnic minorities in the USA to examine endorsement of four diversity ideologies and their relation to minority ethnic and national identification. Because the data was correlational, future research could adopt experimental or longitudinal designs to examine and confirm the extent to which national and ethnic identification are antecedents to ethnic minority endorsement of diversity ideologies (see for example Verkuyten, 2009b, from a majority perspective; although in real life, bi-directional and mutual influences are probably the rule rather than the exception). A 
valuable future direction would also be to examine how colorblindness, as another wellknown diversity ideology (see Hahn et al., 2015; Leslie et al., 2020; Whitley \& Webster, 2019), may compare to the ideologies examined herein. Moreover, a question that comes out of this study is to what degree interculturalism's components manage to fit into one single, overarching construct among minorities. Verkuyten et al. (2020) found that among three large majority group samples in the USA and the Netherlands, the overarching construct did fit the data just as well as when interculturalism was divided into its three components. Future research should examine to what extent this is (or is not) replicable among (a representative sample of) minority and majority respondents in other contexts within and outside of the USA.

As the present findings are the first to contrast ethnic minorities' endorsement of these four diversity ideologies, as well as the differential relationships with their ethnic and national identification, it is important to replicate and extend these findings to other national contexts. Specifically, as the USA tends to be a melting pot nation with only a moderate score on the Multiculturalism Policy Index (Banting \& Kymlicka, 2013), cross-national examination of the research questions explored here may provide greater insight into how the sociocultural norms of the societal context impact on ethnic minorities' experiences with these diversity ideologies. Nevertheless, when thinking of countries with higher scores on the Multiculturalism Policy Index, we imagine that interculturalism, and particularly the components of dialogue and unity, would still be quite strongly supported (see Kymlicka, 2012, for an overview of what constitutes this version of multiculturalism). Moreover, the blurring of group boundaries inherent to polyculturalism and the identity flexibility component of interculturalism may remain secondary to ethnic minorities, as preserving their ethnic identity and distinctiveness may remain a priority regardless of the normative context. 
However, future work should also examine if living in a local context with high levels of diversity or superdiversity (Vertovec, 2007) influences ethnic minority experiences with these ideologies. It may be that in local contexts of superdiversity (e.g. neighborhoods, schools), where cultural mixing and integration of diverse perspectives is normative in everyday life, ethnic minorities may show greater support for intercultural and polycultural perspectives that encourage such blurring of group boundaries. It may also be that support for intercultural and polycultural perspectives is contingent on the type of minority group(s) in question (e.g., native, or "newer" vs. "older" immigrant groups). The present research provides a useful starting point for future exploration into ethnic minorities' support for these diversity ideologies, and how their ethnic and national identification relates to these. 


\section{References}

Alba, R., \& Nee, V. (2003). Remaking the American mainstream: Assimilation and contemporary immigration. Harvard University Press.

Banting, K., \& Kymlicka, W. (2013). Is there really a retreat from multiculturalism policies? New evidence from the multiculturalism policy index. Comparative European Politics, 11, 577-598. http://doi.org/10.1057/cep.2013.12

Barrett, M. (2013). Interculturalism and multiculturalism: Similarities and differences. Strasbourg, France: Council of Europe.

Barry, B. (2001). Culture and equality: An egalitarian critique of multiculturalism. Cambridge, MA: Harvard.

Bernardo, A. B. I., Rosenthal, L., \& Levy, S. R. (2013). Polyculturalism and attitudes towards people from other countries. International Journal of Intercultural Relations, 37, 335344. http://doi.org/10.1016/j.ijintrel.2012.12.005

Bernardo, A. B. I., Salanga, M. G. C., Tjipto, S., Hutapea, B., Yeung, S. S., \& Khan, A. (2016). Contrasting Lay Theories of Polyculturalism and Multiculturalism: Associations With Essentialist Beliefs of Race in Six Asian Cultural Groups. Cross-Cultural Research, 50, 231-250. http://doi.org/10.1177/1069397116641895

Berry, J. W., \& Kalin, R. (1995). Multicultural and ethnic attitudes in Canada: An overview of the 1991 national survey. Canadian Journal of Behavioural Science, 27, 301-320. http://doi.org/doi:10.1037/0008-400X.27.3.301

Bilali, R. (2014). The downsides of national identification for minority groups in intergroup conflicts in assimilationist societies. British Journal of Social Psychology, 53, 21-38. http://doi.org/10.1111/bjso.12012

Bloemraad, I., Korteweg, A., \& Yurdakul, G. (2008). Citizenship and immigration: Multiculturalism, assimilation, and challenges to the nation-state. Annual Review of 
Sociology, 34, 153-179. http://doi.org/10.1146/annurev.soc.34.040507.134608

Bouchard, G. (2011). What is interculturalism? McGill Law Journal, 56, 435-468.

Brewer, M. B. (1991). The social self: On being the same and different at the same time. Personality and Social Psychology Bulletin, 17, 475-482.

Deschamps, J.-C. (1982). Social identity and relations of power between groups. In H. Tajfel (Ed.), Social identity and intergroup relations (pp. 85-98). Cambridge, UK: Cambridge University Press.

Devos, T., \& Mohamed, H. (2014). Shades of American identity: Implicit relations between ethnic and national identities. Social and Personality Psychology Compass, 8, 739-754. http://doi.org/10.1111/spc3.12149

Dovidio, J. F., Gaertner, S. L., \& Saguy, T. (2009). Commonality and the complexity of "we": Social attitudes and social change. Personality and Social Psychology Review, 13, 3-20. http://doi.org/10.1177/1088868308326751

Dovidio, J. F., Gaertner, S. L., Ufkes, E. G., Saguy, T., \& Pearson, A. R. (2016). Included but invisible? Subtle bias, common identity, and the darker side of "we." Social Issues and Policy Review, 10(1), 6-46. http://doi.org/10.1111/sipr.12017

Gaertner, S. L., Dovidio, J. F., Anastasio, P. A., Bachman, B. A., \& Rust, M. C. (1993). The common ingroup identity model: Recategorization and the reduction of intergroup bias. European Review of Social Psychology, 4, 1-26. http://doi.org/https://doi.org/10.1080/14792779343000004

Gale, J., \& Staerklé, C. (2019). Multiculturalism in classically liberal societies: Group membership and compatibility between individual and collective justice. Journal of Experimental Social Psychology, 85. http://doi.org/10.1016/j.jesp.2019.103877

Gordon, M. (1964). Assimilation in American life. New York, NY: Oxford University Press. Grant, P. R., \& Robertson, D. W. (2014). Predicting immigrants' attitudes toward 
multiculturalism using a measure of its perceived benefits. Basic and Applied Social Psychology, 36, 209-220. http://doi.org/10.1080/01973533.2014.890622

Green, E. G. T., \& Staerklé, C. (2013). Migration and multiculturalism. In L. Huddy, D. O. Sears, \& J. S. Levy (Eds.), Oxford handbook of political psychology (2nd ed., pp. 852889). Oxford: Oxford University Press.

Guimond, S., de la Sablonnière, R., \& Nugier, A. (2014). Living in a multicultural world: Intergroup ideologies and the societal context of intergroup relations. European Review of Social Psychology, 25, 142-188. http://doi.org/10.1080/10463283.2014.957578

Guimond, S., Richard, J. C., De Oliveira, P., Kamiejski, R., Kteily, N., Kuepper, B., ... Zick, A. (2013). Diversity policy, social dominance, and intergroup relations: Predicting prejudice in changing social and political contexts. Journal of Personality and Social Psychology, 104, 941-958. http://doi.org/10.1037/a0032069

Hahn, A., Banchefsky, S., Park, B., \& Judd, C. M. (2015). Measuring intergroup ideologies: Positive and negative aspects of emphasizing versus looking beyond group differences. Personality and Social Psychology Bulletin, 41, 1646-1664. http://doi.org/10.1177/0146167215607351

Hehman, E., Gaertner, S. L., Dovidio, J. F., Mania, E. W., Guerra, R., Wilson, D. C., \& Friel, B. M. (2012). Group status drives majority and minority integration preferences. Psychological Science, 23(1), 46-52. http://doi.org/10.1177/0956797611423547

Hu, L. T., \& Bentler, P. M. (1999). Cutoff criteria for fit indexes in covariance structure analysis: Conventional criteria versus new alternatives. Structural Equation Modeling, 6, 1-55. http://doi.org/10.1080/10705519909540118

Joppke, C. (2014). The retreat is real-but what is the alternative? Multiculturalism, muscular liberalism, and Islam. Constellations, 21, 286-295. http://doi.org/10.1111/14678675.12090 
Koopmans, R. (2010). Tradeoffs between equality and difference: Immigrant integration, multiculturalism, and the welfare state in cross-national perspective. Journal of Ethnic and Migration Studies, 36, 1-26. http://doi.org/10.1080/13691830903250881

Kymlicka, W. (2012). Multiculturalism: Success, failure, and the future. Washington, DC: Migration Policy Institute.

Lai, K., \& Green, S. B. (2016). The problem with having two watches: Assessment of fit when RMSEA and CFI disagree. Multivariate Behavioral Research, 51, 220-239. http://doi.org/10.1080/00273171.2015.1134306

Leslie, L. M., Bono, J. E., Kim, Y., \& Beaver, G. R. (2020). On melting pots and salad bowls: A meta-analysis of the effects of identity-blind and identity-conscious diversity ideologies. Journal of Applied Psychology, 105, 453-471. http://doi.org/10.1037/apl0000446

Levin, S., Matthews, M., Guimond, S., Sidanius, J., Pratto, F., Kteily, N., ... Dover, T. (2012). Assimilation, multiculturalism, and colorblindness: Mediated and moderated relationships between social dominance orientation and prejudice. Journal of Experimental Social Psychology, 48, 207-212. http://doi.org/10.1016/j.jesp.2011.06.019

Little, T. D., Slegers, D. W., \& Card, N. A. (2006). A non-arbitrary method of identifying and scaling latent variables in SEM and MACS models. Structural Equation Modeling, 13, 59-72. http://doi.org/10.1207/s15328007sem1301_3

Luhtanen, R., \& Crocker, J. (1992). A collective self-esteem scale: Self-evaluation of one's social identity. Personality and Social Psychology Bulletin, 18, 301-318.

Malik, K. (2015). The failure of multiculturalism: Community versus society in Europe. Foreign Affairs, 94, 21-32.

Meer, N., \& Modood, T. (2012). How does interculturalism contrast with multiculturalism? Journal of Intercultural Studies, 33, 175-196. 
http://doi.org/10.1080/07256868.2011.618266

Meer, N., Modood, T., \& Zapata-Barrero, R. (2016). Interculturalism and multiculturalism: Debating the dividing lines. Edinburgh: Edinburgh University Press.

Morris, M. W., Chiu, C., \& Liu, Z. (2015). Polycultural Psychology. Annual Review of Psychology, 66, 631-659. http://doi.org/10.1146/annurev-psych-010814-015001

Morrison, K. R., Plaut, V. C., \& Ybarra, O. (2010). Predicting whether multiculturalism positively or negatively influences White Americans' intergroup attitudes: the role of ethnic identification. Personality \& Social Psychology Bulletin, 36, 1648-61. http://doi.org/10.1177/0146167210386118

Muthén, L. K., \& Muthén, B. O. (n.d.). Mplus User's Guide (Seventh Ed). Los Angeles, CA: Muthén \& Muthén.

Nandi, A., \& Platt, L. (2015). Patterns of minority and majority identification in a multicultural society. Ethnic and Racial Studies, 38, 2615-2634. http://doi.org/10.1080/01419870.2015.1077986

Novoa, C., \& Moghaddam, F. M. (2014). Policies for Managing Cultural Diversity. In V. Benet-Martínez \& Y. Hong (Eds.), The Oxford Handbook of Multicultural Identity (pp. 462-484). Oxford, UK: Oxford University Press.

Phinney, J., \& Ong, A. (2007). Conceptualization and measurement of ethnic identity: Current status and future directions. Journal of Couseling Psychology, 54, 271-281. http://doi.org/10.1037/0022-0367.54.3.271

Plaut, V. C., Garnett, F. G., Buffardi, L. E., \& Sanchez-Burks, J. (2011). "What about me?” Perceptions of exclusion and whites' reactions to multiculturalism. Journal of Personality and Social Psychology, 101, 337-53. http://doi.org/10.1037/a0022832

Plaut, V. C., Thomas, K. M., Hurd, K., \& Romano, C. A. (2018). Do color blindness and multiculturalism remedy or foster discrimination and racism? Current Directions in 
Psychological Science, 27, 200-206. http://doi.org/10.1177/0963721418766068

Postmes, T., Haslam, S. A., \& Jans, L. (2013). A single-item measure of social identification:

Reliability, validity, and utility. British Journal of Social Psychology, 52, 597-617.

http://doi.org/10.1111/bjso.12006

Reicher, S. D., Spears, R., \& Haslam, S. A. (2010). The social identity approach in social psychology. In M. S. Wetherell \& C. T. Mohanty (Eds.), The SAGE handbook of identities (pp. 45-62). London, England: SAGE.

Rosenthal, L., \& Levy, S. R. (2010). The colorblind, multicultural, and polycultural ideological approaches to improving intergroup attitudes and relations. Social Issues and Policy Review, 4, 215-246. http://doi.org/10.1111/j.1751-2409.2010.01022.x

Rosenthal, L., \& Levy, S. R. (2012). The relation between polyculturalism and intergroup attitudes among racially and ethnically diverse adults. Cultural Diversity and Ethnic Minority Psychology, 18, 1-16. http://doi.org/10.1037/a0026490

Rosenthal, L., \& Levy, S. R. (2016). Endorsement of Polyculturalism Predicts Increased Positive Intergroup Contact and Friendship across the Beginning of College. Journal of Social Issues, 72, 472-488. http://doi.org/10.1111/josi.12177

Rosenthal, L., Levy, S. R., \& Moss, I. (2012). Polyculturalism and openness about criticizing one's culture: Implications for sexual prejudice. Group Processes and Intergroup Relations, 15, 149-165. http://doi.org/10.1177/1368430211412801

Sears, D. O., Citrin, J., Cheleden, S. V., \& van Laar, C. (1999). Cultural diversity and multiculturalism: Is ethnic balkanization psychologically inevitable? In D. A. Prentice \& D. T. Miller (Eds.), Cultural divides: Understanding and overcoming group conflict (pp. 35-79). New York: Russell Sage Foundation.

Sen, A. (2006). Identity and violence: The illusion of destiny. New York, NY: Norton.

Simon, B. (2011). Identity and participation in culturally diverse societies. In A. E. Azzi, X. 
Chryssochoou, B. Klandermans, \& B. Simon (Eds.), Identity and participation in culturally diverse societies (pp. 137-157). Oxford, UK: Blackwell Wiley.

Taylor, C. (1992). Multiculturalism and “The Politics of Recognition.” Princeton, New Jersey: Princeton University Press.

Tip, L. K., Zagefka, H., González, R., Brown, R., Cinnirella, M., \& Na, X. (2012). Is support for multiculturalism threatened by... threat itself? International Journal of Intercultural Relations, 36, 22-30. http://doi.org/10.1016/j.ijintrel.2010.09.011

Turner, J. C., Hogg, M. A., Oakes, P. J., Reicher, S. D., \& Wetherell, M. S. (1987). Rediscovering the social group: A self-categorization theory. Oxford: Basil Blackwell.

Urbiola, A., Willis, G. B., Ruiz-Romero, J., Moya, M., \& Esses, V. (2017). Valuing diversity in Spain and Canada: The role of multicultural ideology in intergroup attitudes and intentions to reduce inequalities. International Journal of Intercultural Relations, 56, 25-38. http://doi.org/10.1016/j.ijintrel.2016.10.006

Verkuyten, M. (2005). Ethnic group identification and group evaluation among minority and majority groups: testing the multiculturalism hypothesis. Journal of Personality and Social Psychology, 88, 121-38. http://doi.org/10.1037/0022-3514.88.1.121

Verkuyten, M. (2006). Multicultural recognition and ethnic minority rights: A social identity perspective. European Review of Social Psychology, 17, 148-184.

http://doi.org/10.1080/10463280600937418

Verkuyten, M. (2009a). Self-esteem and multiculturalism: An examination among ethnic minority and majority groups in the Netherlands. Journal of Research in Personality, 43, 419-427. http://doi.org/10.1016/j.jrp.2009.01.013

Verkuyten, M. (2009b). Support for multiculturalism and minority rights: The role of national identification and out-group threat. Social Justice Research, 22, 31-52. http://doi.org/10.1007/s11211-008-0087-7 
Verkuyten, M. (2010). Assimilation ideology and situational well-being among ethnic minority members. Journal of Experimental Social Psychology, 46, 269-275. http://doi.org/10.1016/j.jesp.2009.11.007

Verkuyten, M., \& Martinovic, B. (2012). Immigrants' national identification: Meanings, determinants, and consequences. Social Issues and Policy Review, 6(1), 82-112. http://doi.org/10.1111/j.1751-2409.2011.01036.x

Verkuyten, M., \& Yogeeswaran, K. (2020a). Cultural diversity and its implications for intergroup relations. Current Opinion in Psychology, 32, 1-5. http://doi.org/10.1016/j.copsyc.2019.06.010

Verkuyten, M., \& Yogeeswaran, K. (2020b). Interculturalism and the acceptance of minority groups: The role of political orientation. Social Psychology, 51, 135-140. http://doi.org/10.1027/1864-9335/a000404

Verkuyten, M., Yogeeswaran, K., Mepham, K., \& Sprong, S. (2020). Interculturalism: A new diversity ideology with interrelated components of dialogue, unity, and identity flexibility. European Journal of Social Psychology, 50, 505-519. http://doi.org/10.1002/ejsp.2628

Ward, C., Gale, J., Staerklé, C., \& Stuart, J. (2018). Immigration and multiculturalism in context: A framework for psychological research. Journal of Social Issues, 74, 833-855. http://doi.org/10.1111/josi.12301

Whitley, B. E., \& Webster, G. D. (2019). The relationships of intergroup ideologies to ethnic prejudice: A meta-analysis. Personality and Social Psychology Review, 23, 207-237. http://doi.org/10.1177/1088868318761423

Wilton, L. S., Apfelbaum, E. P., \& Good, J. J. (2019). Valuing differences and reinforcing Them: Multiculturalism increases race essentialism. Social Psychological and Personality Science, 10, 681-689. http://doi.org/10.1177/1948550618780728 
Wolsko, C., Park, B., \& Judd, C. M. (2006). Considering the tower of babel: Correlates of assimilation and multiculturalism among ethnic minority and majority groups in the United States. Social Justice Research, 19, 277-306. http://doi.org/10.1007/s11211-0060014-8

Wolsko, C., Park, B., Judd, C. M., \& Wittenbrink, B. (2000). Framing interethnic ideology: Effects of multicultural and color-blind perspectives on judgments of groups and individuals. Journal of Personality and Social Psychology, 78, 635-654. http://doi.org/10.1037//0022-3514.78.4.635

Yinger, M. (1981). Toward a theory of assimilation and dissimilation. Ethnic and Racial Studies, 4(3), 249-265.

Yogeeswaran, K., \& Dasgupta, N. (2014a). Conceptions of national identity in a globalised world: Antecedents and consequences. European Review of Social Psychology, 25, 189227. http://doi.org/10.1080/10463283.2014.972081

Yogeeswaran, K., \& Dasgupta, N. (2014b). The devil is in the details: Abstract versus concrete construals of multiculturalism differentially impact intergroup relations. Journal of Personality and Social Psychology, 106, 772-89. http://doi.org/10.1037/a0035830

Yogeeswaran, K., Verkuyten, M., \& Ealam, B. (2020). A way forward? The impact of interculturalism on intergroup relations in culturally diverse nations. Group Processes and Intergroup Relations. http://doi.org/10.1177/1368430220918651 


\section{Item wording}

\section{Supplementary Material}

\section{Assimilation ideology}

1. People who come to the US should change their behavior to be more like Americans.

2. Foreigners should try harder to adapt to American cultural traditions if they want to stay in the US.

3. The unity of this country is weakened by people of different ethnic and cultural backgrounds sticking to their old ways.

\section{Multicultural ideology}

1. All cultures have their own distinct traditions and perspectives.

2. There are boundaries between different ethnic groups because of the differences between cultures.

3. There are differences between racial and ethnic groups, which are important to recognize.

4. Each ethnic group has its own strengths that can be identified.

5. Each racial and ethnic group has important distinguishing characteristics.

\section{Polycultural ideology}

1. Different cultural groups impact one another, even if members of those groups are not completely aware of the impact.

2. Although ethnic groups may seem to have some clear distinguishing qualities, ethnic groups have interacted with one another and thus have influenced each other in ways that may not be readily apparent or discussed.

3. There are many connections between different cultures.

4. Different cultures and ethnic groups probably share some traditions and perspectives because these groups have impacted each other to some extent over the years.

5. Different racial, ethnic, and cultural groups influence each other.

\section{Intercultural ideology}

Unity

1. Despite the different cultures in the USA, we are all part of a single community.

2. Despite cultural differences, all groups together form American society.

3. Despite all our differences there has to be the feeling that we are one nation and have to do it together.

4. Unity against the background of diversity should be the American motto.

\section{Identity flexibility}

1. The cultural identity of people is not fixed, but very changeable.

2. It is important for our society that people dare to let go of aspects of their cultural identity and incorporate new influences in their sense of self.

3. In our diverse society, new culturally mixed identities are needed. 
4. In a diverse society, what people can become together is more important than what they happen to be.

\section{Dialogue}

1. We can only make progress as a country when we are prepared to enter in open dialogue with each other.

2. Only by really listening to each other, differences can be reconciled.

3. In interactions with people who are different, something new and valuable can develop.

4. Mutual trust will only develop when people are willing to enter in dialogue.

\section{National identification}

1. I identify with America.

2. Being American is very important to who I am.

3. I am proud to be American.

4. I have a strong sense of belonging to America.

\section{Ethnic identification}

1. I identify with my ethnic/racial group.

2. My ethnic/racial membership is very important to who I am.

3. I am proud to be a member of my ethnic/racial group.

4. I have a strong sense of belonging to my ethnic/racial group.

\section{Table A1}

Standardized regression coefficients (standard errors) and confidence intervals for model including national and ethnic identification predicting six diversity ideologies, controlling for age, gender, education, income, and ethnicity

\begin{tabular}{|c|c|c|c|c|}
\hline \multirow[b]{2}{*}{ Diversity ideology } & \multicolumn{2}{|c|}{ National identification } & \multicolumn{2}{|c|}{ Ethnic identification } \\
\hline & $b(S E)$ & $95 \% C I$ & $b(S E)$ & $95 \% C I$ \\
\hline AS & $.29 * * *(.06)$ & {$[.18, .41]$} & $-.23 * * *(.06)$ & {$[-.34,-.11]$} \\
\hline $\mathrm{MC}$ & $(.06)$ & {$[-.05, .18]$} & $.37 * * *(.06)$ & {$[.27, .48]$} \\
\hline PC & $(.06)$ & {$[.01, .24]$} & $.27 * * *(.06)$ & {$[.16, .38]$} \\
\hline IU & $.37 * * *(.06)$ & {$[.26, .47]$} & $(.06)$ & {$[-.01, .22]$} \\
\hline IF & $(.07)$ & {$[.01, .27]$} & $.23 * * * \quad(.07)$ & {$[.10, .35]$} \\
\hline ID & $(.06)$ & {$[-.05, .18]$} & $.35 * * *(.06)$ & {$[.24, .46]$} \\
\hline
\end{tabular}

Note. AS represents assimilation, MC represents multiculturalism, PC represents polyculturalism, IU represents Sense of Unity dimension of Interculturalism, IF represents Identity Flexibility dimension of Interculturalism, ID represents Dialogue dimension of Interculturalism. $b$ represents unstandardized regression coefficients, $S E$ represents standard error, 95\% CI represents $95 \%$ confidence interval. Ethnicity is represented as three dummy coded variables (African American as the reference group). $* * * p<.001, * * p<.01, * p<.05$. 


\section{Figure A1}

Structural equation model including factor loadings and paths for the retained measurement model

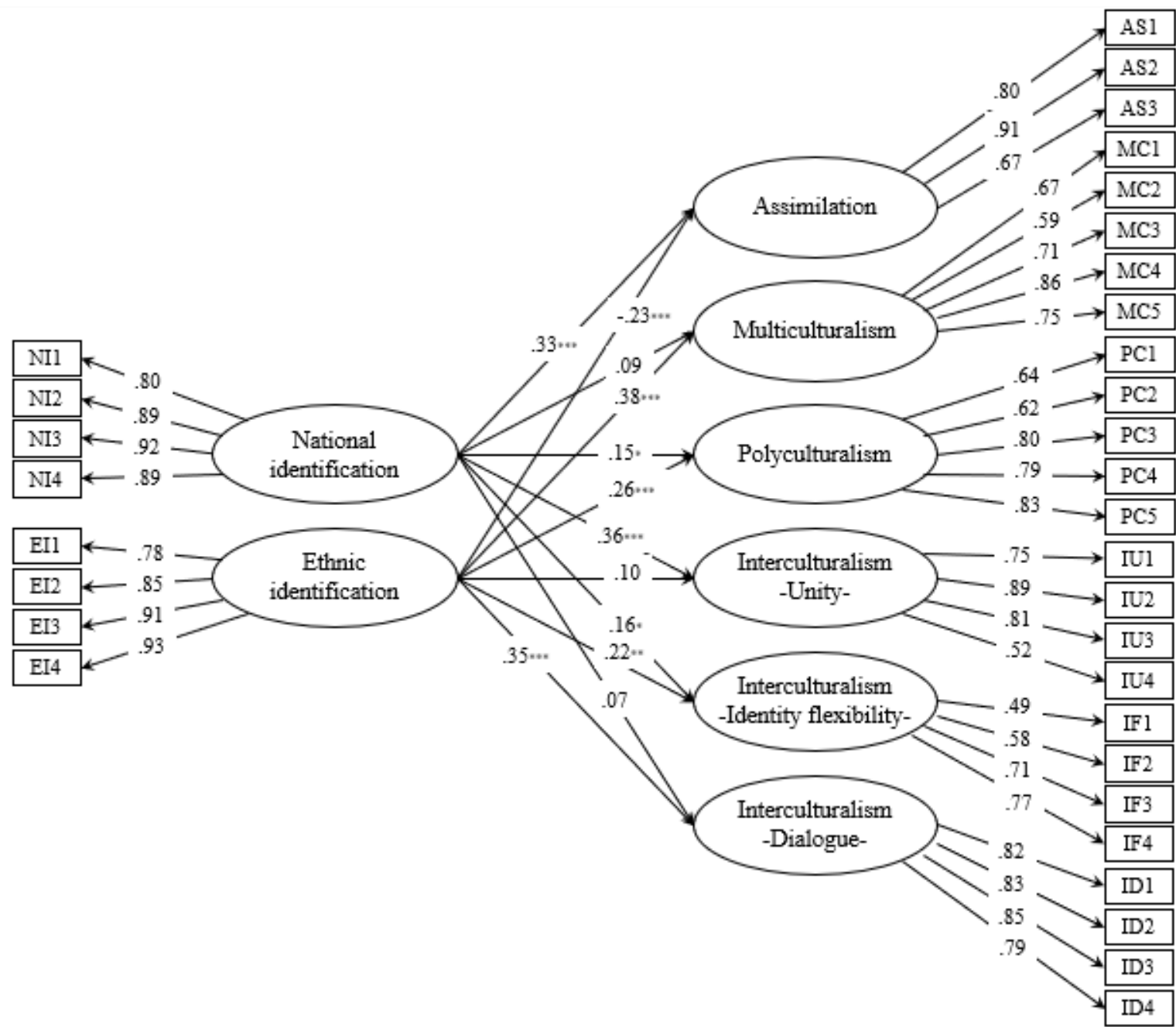

